
D:\Nsurg\Vol. 23, No. 4, Oct. - Dec., 2019\Nsurg-4.Doc
Fig. 1-2 Color
(A)
P. $339-346$
III

ORIGINAL ARTICLE

\title{
Spectrum of Different Spinal Disorders Presenting to Neurosurgical Department of Public Sector Tertiary Care Hospitals of Peshawar
}

\author{
ADNAN AHMED, MOHAMMAD ISHAQ, MUMTAZ ALI, MUSAWER KHAN \\ SOHAIL AHMAD, SYED NASIR SHAH, SAJJAD AHMAD, MANSOOR AHMAD \\ ADNAN KHALIQ \\ Department of Neurosurgery, Lady Reading Hospital, Medical Teaching Institution \\ Peshawar-Pakistan
}

DOI: https://doi.org/10.36552/pjns.v23i4.391

\begin{abstract}
Objectives: To assess the spectrum of different spinal disorders presenting to the Neurosurgical department of public sector tertiary care hospitals of Peshawar.

Materials and Methods: This was a retrospective study carried out in the Neurosurgery departments of two public sector tertiary care hospitals in district Peshawar from January 2012 to December 2018. Our inclusion criteria comprised of all those patients who were having spinal abnormalities irrespective of age and gender, admitted either via emergency or OPD. We excluded those patients who were dead on arrival or whose data was lacking including those who did not do their follow up and those who were not given consent for the study.
\end{abstract}

Results: Out of total 5,579 patients, male to female ratio was 1:1.7. The age range was from 6 days to 78 years. Elective cases were $63.61 \%(n=3,549)$ and emergency were $36.37 \%(n=2,030)$. TSCI were $35.01 \%(n=1,953)$ and NTSCI were 3,626 $(n=64.99 \%)$. Out of all patients, $91.03 \%(n=5,079)$ were treated surgically. About $79 \%$ $(n=4,406)$ had a good outcome.

Conclusion: We collected data and made a survey of the spectrum of different spinal abnormalities resulting from various etiologies focused over the last 6 years. We found a variety of cases presenting to our departments of neurosurgery. Non traumatic spinal injuries are more frequent as compared to traumatic ones.

Keywords: Traumatic spinal injuries, Non traumatic spinal injuries, epidemiology, WHO spinal injury database.

\section{INTRODUCTION}

Spinal cord abnormalities are devastating conditions that results in functional, psychological and social problems. Its incidence is different between different countries across the globe and is estimated at 15-40 cases per million population. ${ }^{1}$ It is documented that damage to neural elements in the spinal canal (spinal cord and cauda equina) results in temporary or permanent neurological deficit that arises from different causes including trauma. Spinal cord lesions can result from different causes that is broadly grouped into two categories, (a) traumatic spinal cord injury (TSCI) and (b) Non traumatic spinal cord injury (NTSCI). TSCI is the commonest type and accounts for the largest proportion of the population. ${ }^{2}$ TSCI occurs when an external physical impact occurs, that damages the spinal cord acutely. The major causes of TSCI in developing countries are motor vehicle accidents, falls and assaults, with motor vehicle accidents being on top (41.4\%). Complete spinal injuries $(56.5 \%)$ are more frequent than incomplete spinal injuries $(43.5 \%))^{2-4}$ Non traumatic spinal cord injury (NTSCI) is defined as any spinal cord damage that has not been caused by any external trauma and 
results from an acute or chronic disease process. Another term used for NTSCI is spinal cord damage or spinal cord myelopathy. According to the literature major causes of NTSCI include degenerative spine diseases, neoplasms (benign or malignant), infections, congenital and developmental, vascular and autoimmune disorders. ${ }^{4-8}$ These NTSCI occurs at any age and its incidence is more than that of TSCI. ${ }^{9}$ It may be the case in the developed countries but it is proposed that incidence of NTSCI will increase in coming years due to aging population. ${ }^{10,11}$

Spinal cord injuries have serious physical, social and vocational effects for patients and their families and results in loss of independence and permanent high lifelong mortality rates. Secondly, costs for care of patients with spinal cord damage in much more which highlights the importance of prevention that we can deliver. The development of effective treatment modalities is critically important for those patients in whom we can't prevent spinal cord injuries. ${ }^{9}$ Thereby it is important to have an idea about the extent of problem in terms of demographics, etiology and outcome, in order to implement appropriate preventive and treatment strategies. ${ }^{12}$

\section{MATERIALS AND METHODS}

\section{Study Design}

It was a retrospective study conducted at neurosurgery departments of public sector tertiary care hospitals of district Peshawar, KPK province of Pakistan from January 2012 to December 2018. Approval for the study was taken from ethical committee Lady Reading hospital, Peshawar.

\section{Inclusion Criteria}

Our inclusion criteria comprised of all those patients who were having spinal abnormalities irrespective of age and gender, admitted either via. emergency or OPD (including referral cases from other centers/ units). Both conservatively and surgically treated patients were included.

\section{Exclusion Criteria}

We excluded those patients who were dead soon after arrival. We also excluded those patients whose data was lacking including those who did not do their follow up and those who did not give consent for the study.

\section{Data Collection}

The data was collected from hospital database, ward/ O.T and emergency registers, patient record files and follow up details. Data was entered in a designed Proforma comprising of patient demographics, type of disease, level of disease, cause of spinal cord injury, treatment modality and outcome of treatment. Three months post treatment outcome was assessed in terms of relief of symptoms, complications and mortality. It was measured as good, satisfactory and poor.

The outcome was measured as "Good", if no complications occurred and the patient became totally free of disease with return of normal routine daily activities. "Satisfactory" outcome was labelled if little relief of symptoms with no complications and routine daily activities of the patient were disturbed. Whereas "Poor" outcome meant if no relief of symptoms or little relief of symptoms occurred along with complications.

\section{Data Analysis}

The data was analyzed using SPSS version 20.

\section{RESULTS}

\section{Age Incidence}

Total number of patients were 5,914. Out of which 335 patient's data was lacking so 5,579 patients were included in the study as per inclusion criteria. The age range was from 6 days to 78 years.

\section{Gender Distribution}

Male patients were $58.82 \%(\mathrm{n}=3,282)$ and female were $41.17 \%(\mathrm{n}=2,297)$. Male to female ratio was 1.7:1.

\section{Clinical Presentation}

Elective cases were $63.61 \%(\mathrm{n}=3,549)$ and emergency were $36.37 \%(\mathrm{n}=2,030)$. TSCI were $35.01 \%(\mathrm{n}=1,953)$ and NTSCI were 3,626 $(\mathrm{n}=$ $64.99 \%$ ). The proportion of each disease in TSCI group and NTSCI group is shown in graph 1 and graph 2 respectively. The distribution of each disease in each group is shown in tables 1-5. Out of all patients $91.03 \%(\mathrm{n}=5,079)$ were treated surgically and $8.96 \%$ $(\mathrm{n}=500)$ were treated conservatively. 


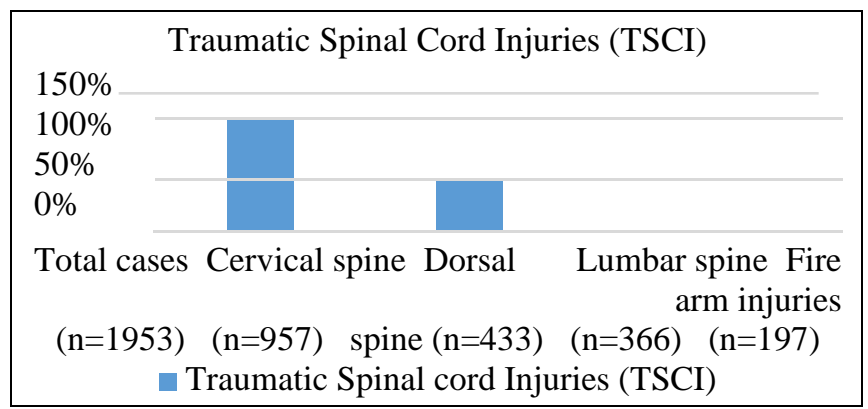

\section{Outcome}

Regarding the outcome, $78.97 \%(\mathrm{n}=4,406)$ had a good outcome, $15.27 \%(\mathrm{n}=852)$ had satisfactory outcome and $3.06 \%(\mathrm{n}=171)$ had poor outcome, while $2.68 \%(\mathrm{n}=150)$ died during this study.

Graph 1: Traumatic Spinal Cord Injuries.

\section{Non Traumatic Spinal Cord Injury (NTSCI) \\ $n=3626$}

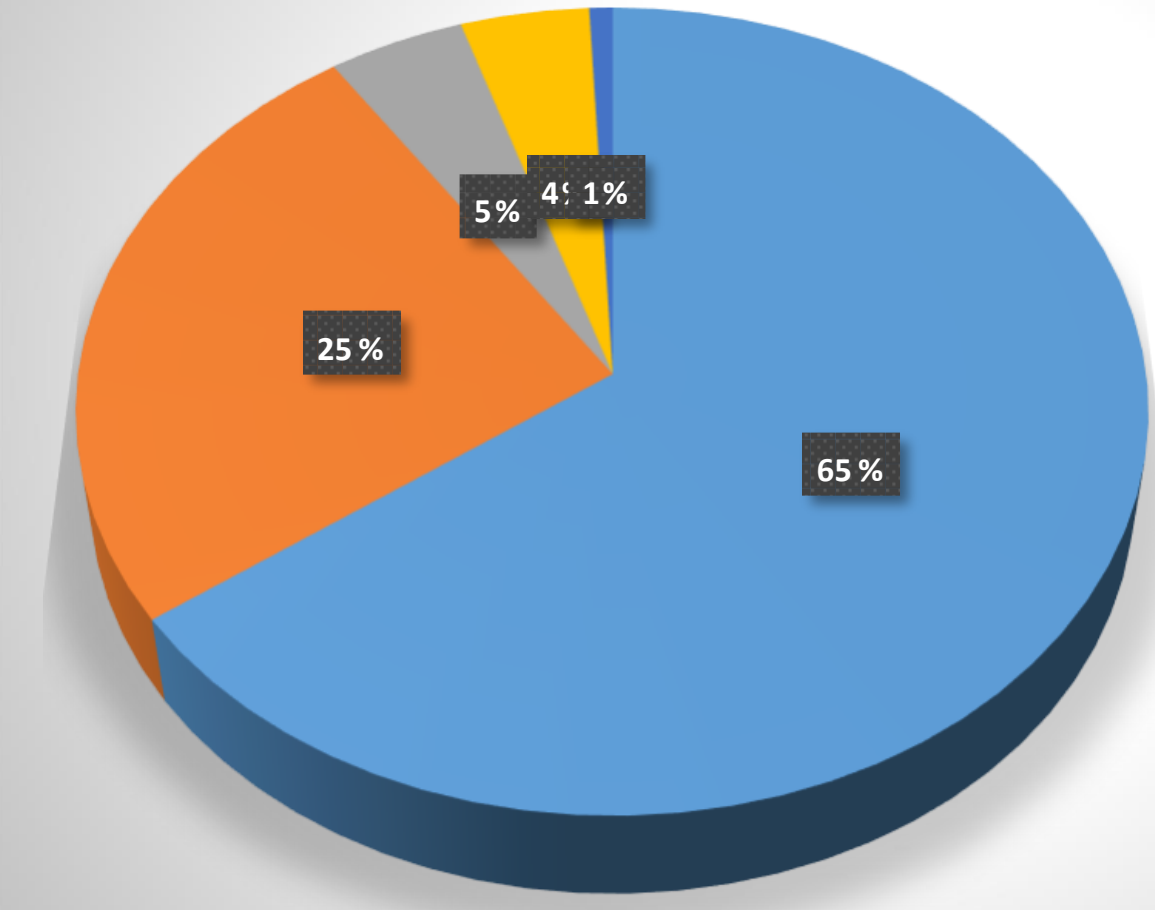

Degenerative $(n=2363)$

Congenital \& Developmental ( $n=919)$

Tumors $(\mathrm{n}=163)$

Infections ( $=153)$

Miscellaneous $(n=28)$

Graph 2: Non-traumatic Spinal Cord Injury.

Table 1: Distribution of Disease.

\begin{tabular}{|c|c|c|c|c|c|c|c|}
\hline Total & \multicolumn{2}{|c|}{ Cervical Spine } & \multicolumn{3}{c|}{ Dorsal Spine } & \multicolumn{3}{c|}{ Lumber Spine } \\
\hline & PIVD & Stenosis/Myelopathy & PIVD & Stenosis/Myelopathy & PIVD & Stenosis & Spondylolisthesis \\
\hline & 357 & 431 & 04 & 07 & 915 & 566 & 83 \\
\hline $\mathbf{2 3 6 3}$ & \multicolumn{3}{|c|}{$\mathbf{7 8 8}$} & \multicolumn{3}{|c|}{$\mathbf{1 1}$} & \multicolumn{3}{|c|}{} \\
\hline
\end{tabular}


Table 2: Type of Disease.

\begin{tabular}{|l|c|c|}
\hline Type of Disease & $\begin{array}{c}\text { Number } \\
\text { Cases of }\end{array}$ & Total \\
\cline { 1 - 2 } Meningocele/Myelomeningocele & 689 & \\
\cline { 1 - 2 } Tethered Cord Syndrome & 208 & \multirow{2}{*}{1045} \\
\cline { 1 - 2 } Arnold Chiari malformation & 97 & \\
\cline { 1 - 2 } CVJ bony Anomalies & 51 & \\
\hline
\end{tabular}

Table 3: Type of Tumor.

\begin{tabular}{|l|c|c|}
\hline Type of Tumor & $\begin{array}{c}\text { Number of } \\
\text { Cases }\end{array}$ & Percentage \\
\hline Extradural & 48 & 25.80 \\
\hline Intradural extramedullary & 71 & 38.17 \\
\hline Intramedullary & 67 & 36.02 \\
\hline Total & 186 & 100 \\
\hline
\end{tabular}

Table 4: Cases of Carries Spine and Hydatid Cyst.

\begin{tabular}{|c|c|c|c|c|}
\hline \multicolumn{3}{|c|}{ Carries Spine } & $\begin{array}{c}\text { Hydatie } \\
\text { Cyst }\end{array}$ & Total \\
\hline $\begin{array}{c}\text { Cervical } \\
\text { Spine } \\
14\end{array}$ & $\begin{array}{c}\text { Dorsal } \\
\text { Spine } \\
111\end{array}$ & $\begin{array}{c}\text { Lumbar } \\
\text { Spine } \\
47\end{array}$ & 03 & 175 \\
\hline
\end{tabular}

Table 5: Complications.

\begin{tabular}{|l|c|c|}
\hline Type & Number of Cases & Total \\
\hline Implant Removal & 07 & \\
\cline { 1 - 2 } $\begin{array}{l}\text { Displaced Implant/ } \\
\text { Implant Repositioning }\end{array}$ & 12 & 32 \\
\cline { 1 - 2 } CSF Leak & 13 & \\
\hline
\end{tabular}

Table 6: Outcome.

\begin{tabular}{|c|c|c|c|c|}
\hline Total & \multicolumn{4}{|c|}{ Outcome } \\
\hline & Good & Satisfactory & Poor & Mortality \\
\hline $\mathbf{5 , 5 7 9}$ & $\begin{array}{c}78.97 \% \\
(\mathrm{n}=4,406)\end{array}$ & $15.27 \%(852)$ & $\begin{array}{c}3.06 \% \\
(\mathrm{n}=171)\end{array}$ & $\begin{array}{c}2.68 \% \\
(\mathrm{n}=150)\end{array}$ \\
\hline
\end{tabular}

\section{DISCUSSION}

It is important to understand the factors responsible for spinal cord injuries (SCI). These factors are paramount in injury prevention. ${ }^{13}$ Literature shows that trauma is responsible for the majority of cases of spinal injuries, but our study shows that non traumatic causes are much more frequent as compared to traumatic ones. Those studies describe the demographic data, causes, neurological deficit, clinical outcomes and disabilities related to traumatic etiologies. The major causes of TSCI are road traffic accidents (RTA) followed by a history of falls and assaults. In a study done in Africa RTAs are responsible for $70 \%$ of cases, whereas in Denmark transport related injuries are responsible for $59.6 \%$ cases. $^{13,14}$ In a study done in Mexico, $41.3 \%$ cases were due to road traffic accidents while $30.9 \%$ were due to history of falls. In South Asia falls are responsible for $40 \%$ of traumatic spinal injuries. ${ }^{15} \mathrm{~A}$ study done by Mathur et al in India found that $53 \%$ patients had a history of fall. ${ }^{16}$ Assaults, including firearm injuries are the third most common cause responsible for TSCI. A study done in South America showed $16.8 \%$ cases of firearm injuries, whereas a Brazilian study showed $42 \%$ cases, while it was $25 \%$ in a study from Turkey and $21 \%$ from Africa. ${ }^{17,18,13}$ Other studies from developed countries showed an incidence of $11.7 \%, 4 \%$ and $2 \%$ from USA, Europe and Canada respectively. ${ }^{18-20}$ According to data from USA National Spinal Cord Injury Statistical Database, NTSCI prevalence is $25-60 \% .^{14,18,19-21}$ In recent studies the more accurate result is $23 \% .^{22}$ Male to female ratio is $55 \%$ vs. $45 \%$ in one study. A study found the average age of 31 years in patients with TSCI. The average age of the patients with NTSCI is more than 30 years in different studies. ${ }^{22,23}$ A study in Mexico has shown 45.2 years as the average age of patients with NTSCI. We found the average age of 39.6 years. The male gender is most frequently affected group. Its incidence is $82.17 \%$ reported in one study. ${ }^{15}$ Such results were shown in other studies as well in which TSCI was higher in males as compared to females. This male to female ratio is a bit more balanced in NTSCI group. ${ }^{24}$ A study found NTSCI in the thoracic region $(71.3 \%)$ more frequently and they attributed this to fact that spinal tumors that compress the cord are mostly found in dorsal spine. As we are concerned only with the spinal diseases, so we found lumber region to be more affected because of higher prevalence of lumber degenerative spinal diseases. We also found more tumor incidence in the dorsal 
spine region. Other studies have shown the same results. ${ }^{21,23-25}$ Other studies have found more incidence of TSCI as compared to TSCI. A study by Cosar et al found this incidence as $23 \%$ vs. $77 \% .{ }^{26}$ Our results are the same if we exclude the degenerative spinal diseases and congenital spinal diseases below L2 level. Battie et al in his study found that the prevalence of degenerative spine disease ranges from $20-83 \% .^{22}$ Matsumoto and colleagues found that degenerative spine disease is more frequent in cervical spine $(86 \%$ in men and $89 \%$ in women above the age of 60 years). ${ }^{27}$ Hanagai et al and Kanayma et al, found highest prevalence of degenerative spine disease in the lumber region, $67 \%$ and $49.5 \%$ respectively. ${ }^{28,}{ }^{29}$ Our findings are consistent with these results. Older age was associated with degenerative spine disease in each region and is more common in the male gender.

A study found $67 \%$ spinal cord abnormalities with complicated bony malformations whereas $37 \%$ cases had simple abnormalities. ${ }^{30} 55 \%$ of children with congenital bony pathology had associated spinal neural axis abnormality. ${ }^{31-34}$ Basu in his study found that incidence of spinal cord abnormalities is highest in cervical and thoracic regions, however they only included patients with hemivertebrae in cervical, thoracic and lumber region. ${ }^{30}$ Another study found $70 \%, 61 \%$ and $54 \%$ incidence of congenital spinal abnormality in cervical, lumber and thoracic regions respectively. ${ }^{35}$

Duong et al in 2012 concluded that incidence rates of benign primary spinal tumors $(0.76 / 100,000)$ were higher than malignant tumors $(0.22 / 100,000)$.In children, the incidence of malignant tumors is more as compared to those of adults. ${ }^{36}$ In a study done in Croatia, Materljan et al., found the incidence of benign spinal tumors as $1.60 / 100,000 .{ }^{37}$ The hospital based incidence was found to be $0.24 / 100,000$ persons per year in a study in India. Primary malignant spinal cord tumors and vertebral tumors comprised of $32.58 \%$, benign tumors were $67.42 \%$. Mets were present in $16.38 \%$ cases. $^{38}$

Spinal tuberculosis is apparently the primary cause of non-traumatic spinal cord lesions in Africa and, together with neoplasms, represents almost half of the causes. Lee found $85 \%$ of spinal infections as tuberculous spine infections, whereas in his another study, he reported $70.1 \%$ cases of tuberculous spine infections. ${ }^{39,40}$ Kim et al found that pyogenic spondylodiscitis is more as compared to Tuberculous spondylodiscitis $(62.7 \%$ vs. $37.3 \%){ }^{41}$ In another study, the pyogenic infection was $78.3 \%$ as compared to tuberculous spine infection $(21.7 \%)$. The in hospital mortality in studies published on TSCI groups is different in different regions. It is $10.8-34.6 \%$ in Africa, 3.1-12.6\% in USA, 1.4-3.4\% in the Western Pacific (only China) and $1.115 .9 \%$ in Europe. ${ }^{42}$ In adult group the mortality was $23.1 \%$. In another study of two adult NTSCI population, the in hospital deaths varied from $9.6 \%$ to $11.4 \%$ cases. ${ }^{43,44}$ In our study, the mortality was $2.68 \%$.

\section{LIMITATIONS/RECOMMENDATIONS}

The limitation of this study was that data was collected from only two tertiary care hospitals of district Peshawar. So these results are not a true representative of entire province or country. Epidemiological data for spinal injuries are required to increase the allocation of health care related resources in the form of budgeting and establishing separate research units aiming at preventing, treating \& rehabilitating and innovative research work for treating these abnormalities. Further research will demonstrate a significant rise in the incidence of SCIs in the coming years. This knowledge can help in healthcare planning in our country.

\section{CONCLUSION}

We collected data and made a survey of spectrum of different spinal abnormalities resulting from various etiologies focused over the last 6 years. Scarcity of data, incomplete information and lack of proper standardized classification are obvious hurdles for definite conclusion. Standard registration of spinal cord injuries (SCI) is needed for prevention, treatment and further research work. We found a variety of spinal abnormalities in our study and a lot of burden on public sector tertiary care hospitals. Non traumatic spinal injuries are more frequent as compared to traumatic ones.

\section{REFERENCES}

1. Sekhon LH, Fehlings MG. Epidemiology demographics, and pathopysiology of acute spinal cord injury. Spine, 2001; 26: S2-12.

2. McKinley WO, Seel RT, Gadi RK, Tewksbury MA. Nontraumatic vs. traumatic spinal cord injury: a rehabilitation outcome comparison. Am J Phys Med Rehabil. 2001; 80: 693-699.

3. Majdan M, Brazinova A, Mauritz W. Epidemiology of traumatic spinal cord injuries in Austria 2002-2012. Eur Spine J. 2015; 25: 62-73. 
4. Löfvenmark I, Norrbrink C, Nilsson-Wikmar L, Hultling C, Chakamdinakira S, Hasselberg $\mathrm{M}$. Traumatic spinal cord injury in Botswana: characteristics, aetiology and mortality. Spinal Cord, 2015; 53: 150-154.

5. Wyndaele M, Wyndaele J-J. Incidence, prevalence and epidemiology of spinal cord injury: what learns a worldwide literature survey? Spinal Cord, 2006; 44: 523-529.

6. New PW, Cripps RA, Bonne Lee B. Global maps of non-traumatic spinal cord injury epidemiology: towards a living data repository. Spinal Cord, 2014; 52: 97-109.

7. New PW, Sundararajan V. Incidence of non-traumatic spinal cord injury in Victoria, Australia: a population based study and literature review. Spinal Cord, 2008; 46: 406-411.

8. McKinley MO, Tewksbury MA, Goodbout CJ. Comparison of medical complications following nontraumatic and traumatic spinal cord injury. J Spinal Cord Med. 2002; 25: 88-93.

9. Center, N.S.C.I.S. Spinal Cord Injury Facts and Figures at a Glance. The Journal of Spinal Cord Medicine, 2014; 37: 117-118.

Doi:10.1179/1079026813z.000000000249.

10. Singh, A., Tetreault, L., Kalsi-Ryan, S., Nouri, A. \& Fehlings, M. G. Global prevalence and incidence of traumatic spinal cord injury. Clin Epidemiol. 2014; 6: 309-331. Doi:10.2147/CLEP.S68889.

11. Chen Y, He Y, De Vivo M. J. Changing Demographics and Injury Profile of New Traumatic Spinal Cord Injuries in the United States, 1972-2014. Arch Phys Med Rehabil. 2016; 97: 1610-1619. Doi:10.1016/j.apmr

12. Ibrahim A, Lee KY, Kanoo LL, Tan CH, Hamid MA, Hamedon NM et al. Epidemiology of spinal cord injury in hospital Kuala Lumpur. Spine, 2013; 38: 419-424.

13. Fielingsdorf K, Dunn RN. Cervical spine injury outcome-a review of 101cases treated in a tertiary referral unit. S Afr Med J. 2007; 97: 203-207.

14. Bjornshave Noe B, Mikkelsen EM, Hansen RM, Thygesen M, Hagen EM. Incidence of traumatic spinal cord injury in Denmark 1990-2012: a hospital-based study. Spinal Cord, 2015; 53: 436-440.

15. Alshahari SS, Cripps RA, Lee BB, Al-Jadid MS. Traumatic spinal cord injury in Saudi Arabia: an epidemiological estimate from Riyadh. Spinal Cord, 2012; 50: 882-884.

16. Mathur N, Jain S, Kumar N, Srivastava A, Purohit N, Patni A. Spinal cord injury: scenario in an Indian state. Spinal Cord, 2015; 53: 349-352.

17. Costacurta ML, Taricco LD, Kobaiyashi ET, Cristante AR. Epidemiological profile of a pediatric population with acquired spinal cord injury from AACD: Sao Paulo/Brazil. Spinal Cord, 2010; 48: 118-121.

18. Ones K, Yilmaz E, Beydogan A, Gultekin O, Caglar N. Comparison of functional results in non-traumatic and traumatic spinal cord injury. Disabil Rehabil. 2007; 29:
1185-1191.

19. DeVivo MJ, Chen Y. Trends in new injuries prevalent cases, and aging with spinal cord injury. Arch Phys Med Rehabil. 2011; 92: 332-338.

20. Scivloetto G, Farchi S, Laurenza L, Molinari M. Traumatic and non-traumatic spinal cord lesions: an Italian comparison of neurological and functional outcomes. Spinal Cord, 2011; 49: 391-396.

21. O'Connor P. Incidence and patterns of spinal cord injury in Australia. Accid Anal Prev. 2002; 34: 405415.

22. Battié MC, Videman T, Parent E. Lumbar disc degeneration. Epidemiology and genetic influences. Spine, 2004; 29: 2679e90.

23. Celani MG, Spizzichino L, Ricci S, Zampolini M, Franceschini M. Spinal cord injury in Italy: a multicenter retrospective study. Arch Phys Med Rehabil. 2001; 82: 589-596.

24. Zárate-Kalfópulos B, Jiménez-González A, ReyesSánchez A, Robles-Ortiz1 R, CabreraAldana E. LM Rosales-Olivarez L. M. Demographic and clinical characteristics of patients with spinal cord injury: a single hospital-based study. Spinal Cord, 2016; 54: 1016-1019.

25. Vervoordeldonk JJ, Post MW, New P. Rehabilitation of patients with traumatic spinal cord injury in the Netherlands: etiology, length of stay and functional outcome. Top Spinal Cord Inj Rehabil. 2013; 19: 195201.

26. Cosar SN, Yemisci OU, Oztop P, Cetin N, Sarifakioglu B, Yalbuzdag SA et al. Demographic characteristics after traumatic and non-traumatic spinal cord injury: a retrospective comparison study. Spinal Cord, 2010; 48: 862-866.

27. Matsumoto M, Fujiwara Y, Suzuki N, Nishi Y, Nakayama M, Yabe $Y$, et al. MRI of cervical intervertebral discs in asymptomatic subjects. J Bone Joint Surg Br. 1998; Vol. 80: 19e24.

28. Hanagai M, Kaneoke K, Kuno S, Hinotsu S, Sakane M, Mamizuka N, et al. Factors associated with lumbar intervertebral disc degeneration in the elderly. Spine J. 2008; 8: 732e40.

29. Kanayama M, Togawa D, Takahashi C, Terai T, Hashimoto T. Cross-sectional magnetic resonance imaging study of lumbar disc degeneration in 200 healthy individuals. J Neurosurg Spine, 2009; 11: $501 \mathrm{e} 7$.

30. Basu P, Elsebaie H, Noordeen M. Congenital spinal deformity: a comprehensive assessment at presentation. Spine, 2002; 27 (20): 2255-2259.

Doi:10.1097/00007632200210150-00014

31. Nagata K, Yoshimura N, Muraki S, Hashizume H, Ishimoto $\mathrm{Y}$, Yamada $\mathrm{H}$, et al. Prevalence of cervical cord compression and its association with physical performance in a population based cohort in Japan: the Wakayama Spine Study. Spine, 2012; 37: 1892e8. 
32. Ibrahim A, Lee KY, Kanoo LL, Tan CH, Hamid MA, Hamedon NM et al. Epidemiology of spinal cord injury in hospital Kuala Lumpur. Spine, 2013; 38: 419-424.

33. Bjornshave Noe B, Mikkelsen EM, Hansen RM, Thygesen M, Hagen EM. Incidence of traumatic spinal cord injury in Denmark 1990-2012: a hospital-based study. Spinal Cord, 2015; 53: 436-440.

34. Fielingsdorf K, Dunn RN. Cervical spine injury outcome-a review of 101 cases treatedcin a tertiary referral unit. S Afr Med J. 2007; 97: 203-207.

35. Trenga A.P, Singla A, Feger M. A, Abel M. F. Patterns of congenital bony spinal deformity and associated neural anomalies on X-ray and magnetic resonance imaging .J Child Orthop. 2016; 10: 343-352.

Doi:10.1007/s11832-016-0752-6

36. Duong LM, McCarthy BJ, McLendon RE, Dolecek TA, Kruchko C, Douglas LL, et al. Descriptive epidemiology of malignant and nonmalignant primary spinal cord, spinal meninges, and cauda equina tumors, United States, 2004-2007. Cancer, 2012; 118: 4220-7.

37. Materljan E, Materljan B, Sepcic J, Tuskan-Mohar L, Zamolo G, Erman-Baldini I. Epidemiology of central nervous system tumors in Labin area, Croatia, 19742001. Croat Med J. 2004; 45: 206-12.

38. Bhat A. R, Kirmani A. R, Wani M. A, Bhat M. H. Incidence, histopathology, and surgical outcome of tumors of spinal cord, nerve roots, meninges, and vertebral column - Data based on single institutional (Sher-i-Kashmir Institute of Medical Sciences) experience. J Neurosci Rural Pract. 2016; 7 (3): 381391. Doi:10.4103/0976-3147.181489.

39. Lee KS, Doh JW, Bae HG, Yun IG. Primary infections disorders of the spine: report of 40 cases. J Korean Neurosurg Soc. 1996; 25: 1655-1660.

40. Lee KY, Sohn SK, Hwang KS. Comparison of pyogenic and tuberculous spondylitis. J Korean Soc Spine Surg. 1999; 6: 443-450.

41. Kim HW, Jeong S. Choi S, Youm J, Ha H.G, Yi J. S, Microbiology and Epidemiology of Infectious Spinal Disease. J Korean Neurosurg Soc. 2014; 56 (1): 21-27.

42. Chamberlain J. D, Meier S, Mader L, von Groote P. Martin W.G. Brinkhof M. W.G .Mortality and Longevity after a Spinal Cord Injury: Systematic Review and Meta-Analysis. Neuroepidemiology, 2015; 44: 182-198. Doi:10.1159/000382079

43. Mak KS, Lee LK, Mak RH, Wang S, Pile-Spellman J, Abrahm JL, Prigerson HG, Balboni TA: Incidence and treatment patterns in hospitalizations for malignant spinal cord compression in the United States, 19982006. Int J Radiat Oncol Biol Phys. 2011; 80: 824-831.

44. New PW, Epi MC: Influence of age and gender on rehabilitation outcomes in non-traumatic spinal cord injury. J Spinal Cord Med. 2007; 30: 225-237.

\section{Additional Information}

Disclosures: Authors report no conflict of interest.

Ethical Review Board Approval: The study was conformed to the ethical review board requirements.

Human Subjects: Consent was obtained by all patients/participants in this study.

Conflicts of Interest:

In compliance with the ICMJE uniform disclosure form, all authors declare the following:

Financial Relationships: All authors have declared that they have no financial relationships at present or within the previous three years with any organizations that might have an interest in the submitted work.

Other Relationships: All authors have declared that there are no other relationships or activities that could appear to have influenced the submitted work.

Address for Correspondence:

Dr. Mohammad Ishaq

Assistant Professor, Department of Neurosurgery,

Lady Reading Hospital - Medical Teaching Institution, Peshawar-Pakistan

Email:drmohammadishaq@yahoo.com 


\begin{tabular}{|c|c|c|c|c|}
\hline \multicolumn{5}{|c|}{ AUTHORSHIP AND CONTRIBUTION DECLARATION } \\
\hline Sr.\# & Author's Full Name & \multicolumn{2}{|c|}{ Intellectual/Contribution to Paper in Terms of: } & \multirow{10}{*}{$\begin{array}{l}\text { Signature by the } \\
\text { author(s) }\end{array}$} \\
\hline 1. & $\begin{array}{l}\text { Adnan Ahmed } \\
\text { (Main/Principal Author). }\end{array}$ & \multirow{2}{*}{\multicolumn{2}{|c|}{$\begin{array}{l}\text { 1. Proposed topics and Basic Study Design, } \\
\text { methodology. } \\
\text { 2. Data collection and calculations }\end{array}$}} & \\
\hline 2. & $\begin{array}{l}\text { Mohammad Ishaq } \\
\text { (2nd Author) }\end{array}$ & & & \\
\hline 3. & $\begin{array}{l}\text { Mumtaz Ali } \\
\text { (3rd Author) }\end{array}$ & \multirow{3}{*}{\multicolumn{2}{|c|}{$\begin{array}{l}\text { 3. Analysis of data. } \\
\text { 4. Literature review and manuscript writing }\end{array}$}} & \\
\hline 4. & $\begin{array}{l}\text { Musawer Khan } \\
\text { (4th Author) }\end{array}$ & & & \\
\hline 5. & $\begin{array}{l}\text { Sohail Ahmad } \\
\text { (5th Author) }\end{array}$ & & & \\
\hline 6. & $\begin{array}{l}\text { Syed Nasir Shah } \\
\text { (6th Author) }\end{array}$ & \multirow{4}{*}{\multicolumn{2}{|c|}{ 6. Study Design and methodology }} & \\
\hline 7. & $\begin{array}{l}\text { Sajjad Ahmad } \\
\text { (7th Author) }\end{array}$ & & & \\
\hline 8. & $\begin{array}{l}\text { Mansoor Ahmad } \\
\left(8^{\text {th }} \text { Author }\right)\end{array}$ & & & \\
\hline 9. & $\begin{array}{l}\text { Adnan Khaliq } \\
\left(9^{\text {th }} \text { Author }\right)\end{array}$ & & & \\
\hline
\end{tabular}

Date of Submission: 12-10-2019

Date of Revision: 15-11-2019

Date of Online Publishing: 25-12-2019

Date of Print: 31-12-2019 